\title{
Specificity and sensitivity of commercially available assays for glucagon and oxyntomodulin measurement in humans
}

\author{
Monika J Bak ${ }^{1,2}$, Nicolai Wewer Albrechtsen ${ }^{1}$, Jens Pedersen ${ }^{1}$, Bolette Hartmann ${ }^{1}$, \\ Mikkel Christensen ${ }^{3}$, Tina VilsbølI ${ }^{3}$, Filip K Knop ${ }^{3}$, Carolyn F Deacon', \\ Lars O Dragsted ${ }^{2}$ and Jens J Holst ${ }^{1}$ \\ ${ }^{1}$ NNF Center for Basic Metabolic Research, Department of Biomedical Sciences, Faculty of Health Sciences, \\ ${ }^{2}$ Department of Human Nutrition, Faculty of Science, University of Copenhagen, Blegdamsvej 3, Building 12.2, \\ DK-2200 Copenhagen, Denmark and ${ }^{3}$ Department of Medicine, Copenhagen University Hospital Gentofte, \\ Hellerup, DK-2900 Gentofte, Denmark
}

\author{
Correspondence \\ should be addressed \\ to J J Holst \\ Email \\ jjholst@sund.ku.dk
}

\begin{abstract}
Aim: To determine the specificity and sensitivity of assays carried out using commercially available kits for glucagon and/or oxyntomodulin measurements.

Methods: Ten different assay kits used for the measurement of either glucagon or oxyntomodulin concentrations were obtained. Solutions of synthetic glucagon (proglucagon (PG) residues 33-61), oxyntomodulin (PG residues 33-69) and glicentin (PG residues 1-69) were prepared and peptide concentrations were verified by quantitative amino acid analysis and a processing-independent in-house RIA. Peptides were added to the matrix (assay buffer) supplied with the kits (concentration range: $1.25-300 \mathrm{pmol} / \mathrm{l}$ ) and to human plasma and recoveries were determined. Assays yielding meaningful results were analysed for precision and sensitivity by repeated analysis and ability to discriminate low concentrations. Results and conclusion: Three assays were specific for glucagon (carried out using the Millipore (Billerica, MA, USA), Bio-Rad (Sundbyberg, Sweden), and ALPCO (Salem, NH, USA) and Yanaihara Institute (Shizuoka, Japan) kits), but none was specific for oxyntomodulin. The assay carried out using the Phoenix (Burlingame, CA, USA) glucagon kit measured the concentrations of all three peptides (total glucagon) equally. Sensitivity and precision were generally poor; the assay carried out using the Millipore RIA kit performed best with a sensitivity around $10 \mathrm{pmol} / \mathrm{l}$. Assays carried out using the BlueGene (Shanghai, China), USCN LIFE (Wuhan, China) (oxyntomodulin and glucagon), MyBioSource (San Diego, CA, USA) and Phoenix oxyntomodulin kits yielded inconsistent results.
\end{abstract}

\section{Introduction}

Glucagon, oxyntomodulin and glicentin are products of the glucagon gene (GCG) located on chromosome 2q36,37 (1). The peptides arise from differential processing of the glucagon precursor, proglucagon (PG), a peptide consisting of 160 amino acids, but they all have the full glucagon amino acid sequence (2). Glucagon, corresponding to PG residues 33-61, is formed in the pancreas by the action of prohormone convertase (PC) 2 (3). Glicentin, corresponding to PG residues $1-69$, is produced in the gut, where PG is processed by PC1/3 $(4,5)$ (Fig. 1). Part of glicentin may be cleaved to generate oxyntomodulin corresponding to PG residues 33-69 (6). Together, the intestinal products have been designated as 'gut glucagon', 'gut glucagon-like immunoreactivity' or 'enteroglucagon' (7). The remaining part of PG gives rise to a single large peptide, major PG fragment (PG residues 72-158), upon pancreatic processing, and to the two glucagon-like peptides (GLP1 and GLP2) upon intestinal processing $(3,8,9,10,11)$. 


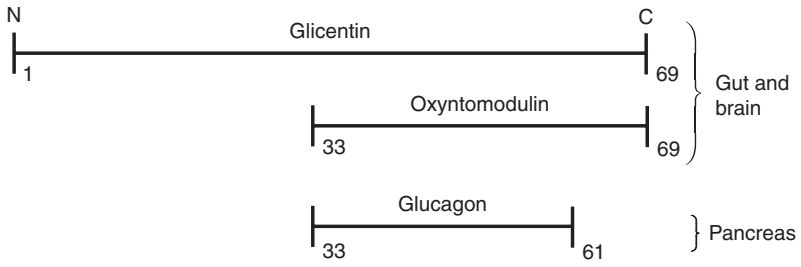

Figure 1

Diagrammatic illustration of the structures of glucagon, oxyntomodulin and glicentin.

Glucagon is secreted by the $\alpha$-cells in the pancreas in response to a decrease in plasma glucose concentrations and in response to increased concentrations of specific amino acids (12). This means that secretion is stimulated by protein-rich meals, but inhibited by carbohydrate-rich meals. Patients with type 2 diabetes are characterised by increased concentrations of fasting glucagon and inappropriate suppression of glucagon during an oral glucose tolerance test $(7,13,14,15)$. Glucagon is a counterregulatory hormone opposing the actions of insulin in glucose homoeostasis $(8,16)$. The secretion of glicentin and oxyntomodulin by the intestinal $\mathrm{L}$ cells is stimulated in parallel with that of GLP1 and GLP2 by the luminal presence of digested nutrients (including carbohydrates, proteins and fat) (9) depending on the size of the meal. The possible biological effects of glicentin are unclear, although an effect on gastric acid secretion has been reported (17). Oxyntomodulin, on the other hand, has been shown in animal and human intervention studies to reduce food intake, with a resulting weight reduction (18). It also has glucagon-like effects on insulin secretion and possibly hepatic glucose production (19). A distinct receptor for oxyntomodulin remains to be identified, but oxyntomodulin interacts with the receptors of both GLP1 and glucagon, albeit with a potency that is 50-100 times less than their respective ligands (20).

Measurements of these three glucagon-containing peptides present several difficulties regarding specificity. The dominating antigenic determinant of the glucagon molecule corresponds to a mid-region of the peptide (13), and antibodies against this region will also recognise oxyntomodulin and glicentin (7). Antibodies with an absolute requirement for the free C-terminus of glucagon will react with glucagon (7), but not with glicentin or oxyntomodulin (but will also react with N-terminally extended molecular forms including PG residues 1-61) (21), while antibodies against the C-terminus of glicentin will recognise both this peptide and oxyntomodulin.
Antibodies against the N-terminus of glicentin will react with glicentin alone (but also with PG, if secreted). The concentrations of gut glucagon (glicentin + oxyntomodulin) have been estimated by the subtraction of results obtained with a C-terminal assay (specific assays) from those measured with antibodies against the mid-region (processing-independent or 'side-viewing' assays, determining 'total glucagon' concentrations) (22). Clearly, therefore, assays for any of these peptides must be fully characterised in terms of their specificity. In addition, as these hormones generally circulate at low concentrations (0-50 pmol/1), adequate sensitivity is also required. The purpose of the present study was to evaluate the specificity and sensitivity of assays carried out using commercially available kits marketed for the determination of glucagon and oxyntomodulin concentrations.

\section{Subjects and methods}

\section{Peptides}

The concentrations of synthetic glucagon 1-29 (Bachem, Bubendorf, Switzerland, Cat. no. H-6790), oxyntomodulin (Bachem, Cat. no. H-6058) and glicentin (GenScript, Piscataway, NJ, USA, custom-made service no. SC1208) were determined by quantitative amino acid analysis (QAAA; duplicate determination) at the Department of Systems Biology, Enzyme and Protein Chemistry (Søltofts Plads, DTU, Kgs. Lyngby, Denmark), as well as by an analysis using an in-house mid-region-specific glucagon RIA employing antiserum code no. 4304 (20). Peptides were dissolved in phosphate buffer containing 1\% human serum albumin (Calbiochem, affiliate of Merck KGaA, Darmstadt, Germany, Cat. no. 12666), and $1 \mu \mathrm{M}$ stock solutions were prepared for each peptide, aliquoted and stored in Nunc tubes (Cat. no. 443990; VWR-Bie\&Berntsen A/S, Herlev, Denmark) at $-20{ }^{\circ} \mathrm{C}$. The peptide concentrations measured by RIA were used for the determination of the amounts of peptides added in recovery studies, as these assays (unlike the QAAA) could be carried out on the albumin-containing stock solutions of the peptides.

\section{Assays}

The assay kits tested are listed in Table 1.

Kits were stored according to the manufacturers' recommendations. Several kits $(n=3-8$, encompassing different lot numbers) were obtained for each assay from different suppliers over a period of 1 year (but all were used immediately upon receipt and well before expiry dates). 


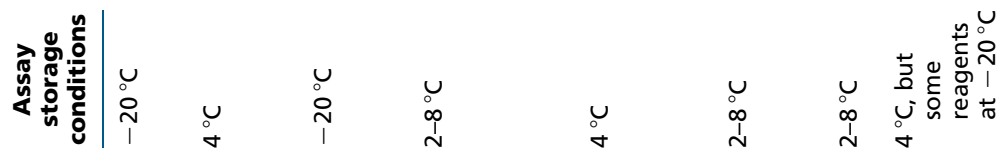

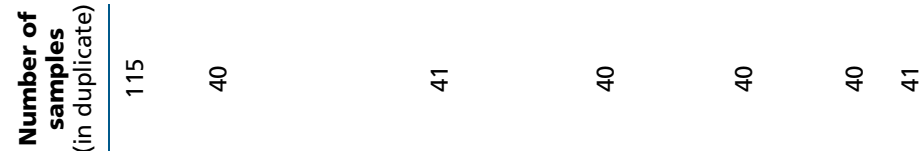

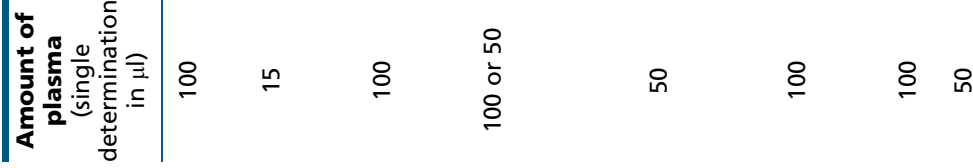

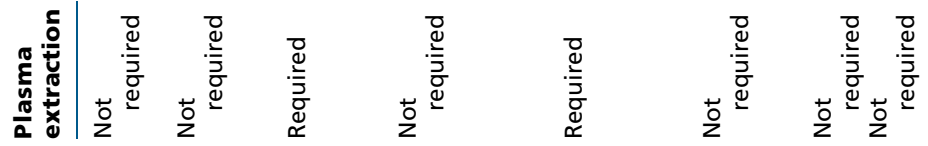

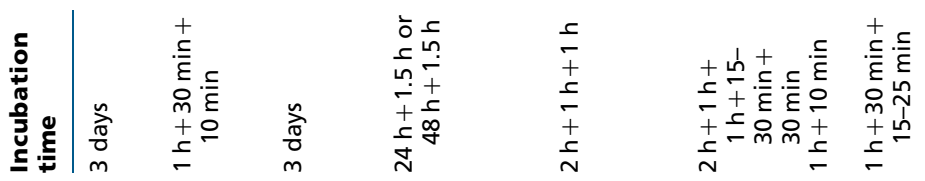

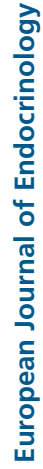

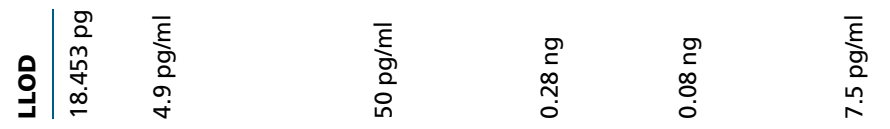

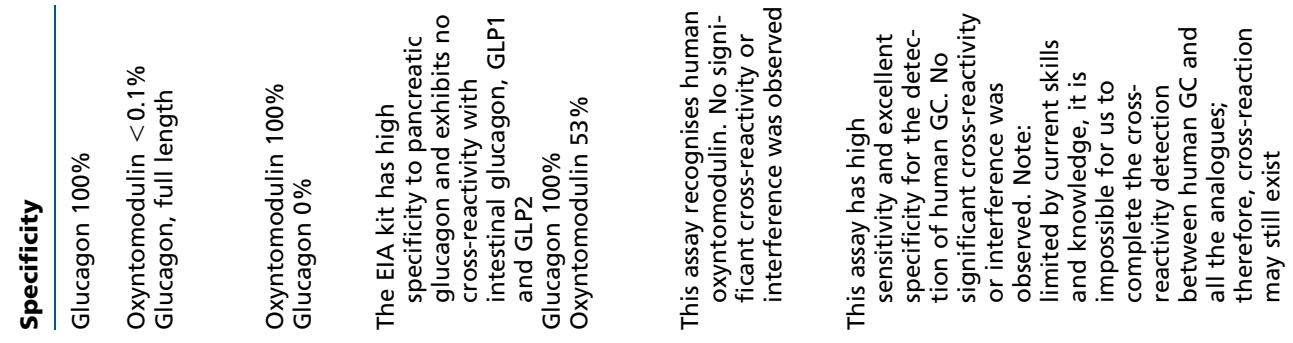

$\frac{\frac{\sqrt[n]{\frac{1}{2}}}{\frac{0}{0}}}{\frac{\pi}{\frac{\pi}{0}}}$

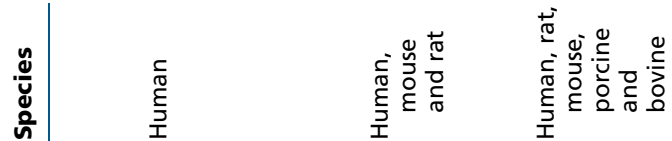

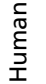

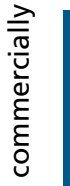

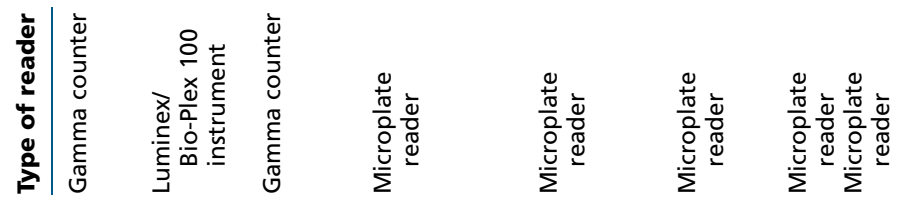

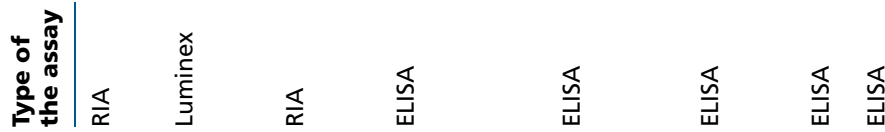

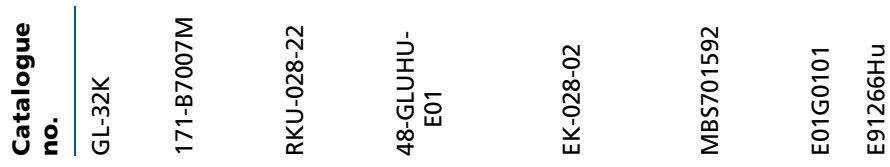

㠃

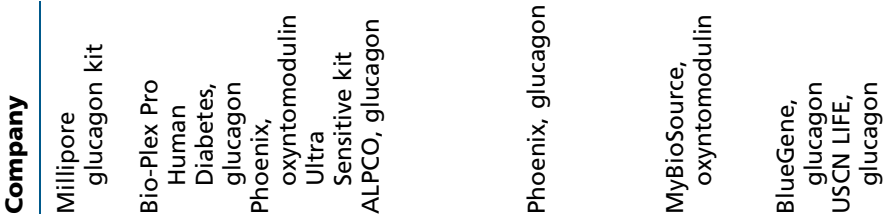




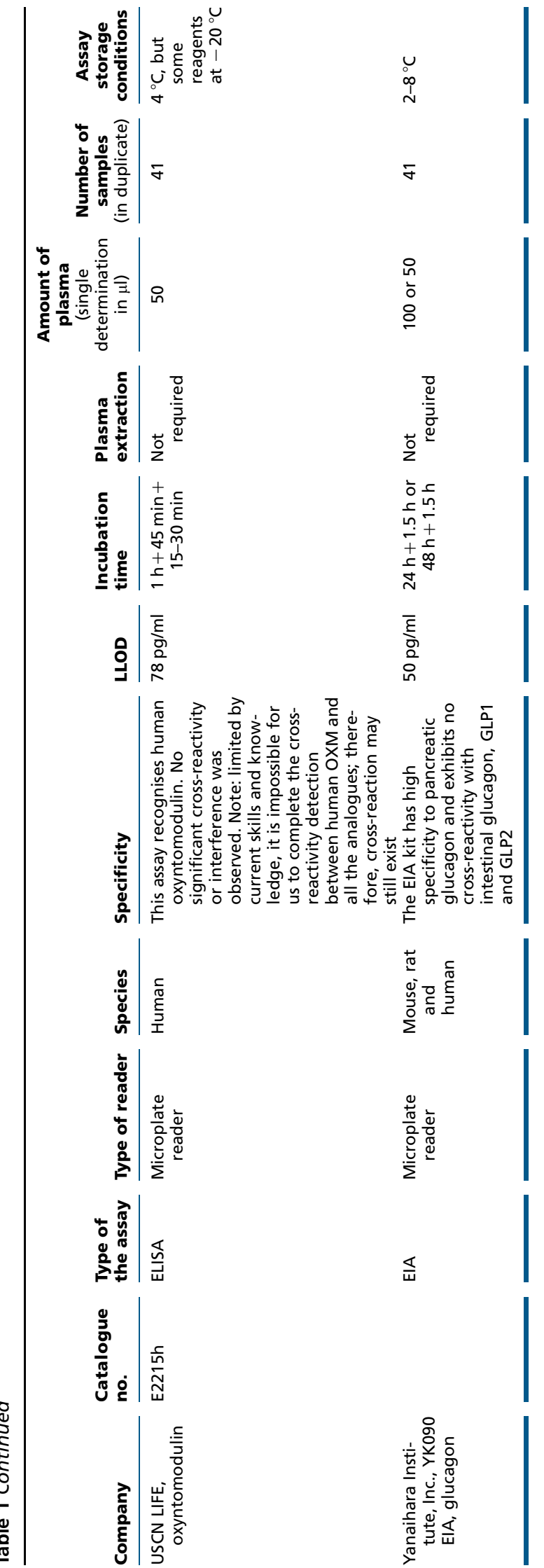

\section{Protocol}

Specificity was analysed from recovery experiments. Known amounts of the peptides were added to the matrix (assay buffer) supplied with each kit to yield final concentrations of $2.5,5,10,20,40,80,160$ and $300 \mathrm{pmol} / \mathrm{l}$ (spiked buffer). Peptides from the same batch were also added to the RIA buffer $(80 \mathrm{mmol} / \mathrm{l}$ sodium phosphate buffer, $\mathrm{pH} 7.5$, containing in addition $0.1 \%$ $\mathrm{wt} / \mathrm{vol}$ human serum albumin, $10 \mathrm{mmol} / \mathrm{l}$ EDTA and $0.6 \mathrm{mmol} / 1$ thimerosal (no. T-5125, Sigma Chemical Co.)) and measured with the in-house RIA 4304 (7). For each assay, one aliquot from each spiked buffer sample was measured in duplicate on three separate occasions using three separate kits.

Human plasma was prepared by pooling plasma samples (collected into tubes containing EDTA) from a total of 15 healthy volunteers, to which aprotinin (Trasylol $10000 \mathrm{KIE} / \mathrm{ml}$; Bayer Health Care AG 51368) was added to give a final concentration of $500 \mathrm{KIE} / \mathrm{ml}$. The pooled plasma was aliquoted and stored at $-20^{\circ} \mathrm{C}$, but was used within 1 year of preparation. Known amounts of the peptides were added to plasma at $0{ }^{\circ} \mathrm{C}$ to give final concentrations ranging from 1.25 to $160 \mathrm{pmol} / \mathrm{l}$ (spiked plasma) and aliquoted into Nunc tubes.

Sensitivity was estimated by determining the lowest concentrations of added peptide that could be measured as being significantly different from 0 (by paired analysis of three duplicate determinations). Precision was determined for assays specific for glucagon (three assays) using a single plasma pool spiked with $0,1,2,5,10,20$ and $40 \mathrm{pmol} / \mathrm{l}$ glucagon respectively and measuring each sample 7-10 times in the same assay run. Means and S.D. were calculated for each concentration. This was done using three different pools of plasma, with intervals of 5-6 months, using different assay batches and different researchers.

The ability of assays carried out using three commercial glucagon-specific kits (ALPCO, Millipore and Bio-Rad) to measure endogenous glucagon concentrations was assessed using reserve plasma samples (collected into tubes containing EDTA plus aprotinin (final concentration $500 \mathrm{KIU} / \mathrm{ml}$ blood) and a specific dipeptidyl peptidase 4 inhibitor (valine pyrrolidide, a gift from Novo Nordisk, Bagsværd, Denmark; final concentration of $0.01 \mathrm{mmol} / \mathrm{l}$ ) and stored at $-20^{\circ} \mathrm{C}$ ) from a previously published human study (22), in which arterialised blood was drawn from each of ten healthy human volunteers. In these individuals, plasma glucose concentrations had been increased with glucose infusions or lowered with insulin injection. 
The same samples were also measured using a fully characterised and validated in-house glucagon-specific RIA employing antiserum code no. 4305 (23). All samples were set up in each of the four assays on the same day.

For all assays, the manufacturers' instructions, including sample preparation by extraction (including purification columns and buffers), were followed closely.

\section{Calculations and statistical analysis}

The concentrations of peptides measured were plotted against the calculated concentrations, after the subtraction of plasma zero values (see an example in Fig. 2), and linear regression analyses were carried out for each individual set of samples. The regression coefficient $r^{2}$ shows the fit of the line, and the slope of the fitted linear lines corresponds to the recovery in the tested assay; for the slopes of each peptide and assay, $P$ values were calculated for the null hypothesis: horizontal line. Correlation was calculated using Pearson's distribution. All calculations were done using GraphPad Prism ver 5.0 (La Jolla, CA, USA).

\section{Results}

\section{Synthetic peptide verification}

The concentrations of the peptides, expressed as percentages of the expected concentrations, were as follows:

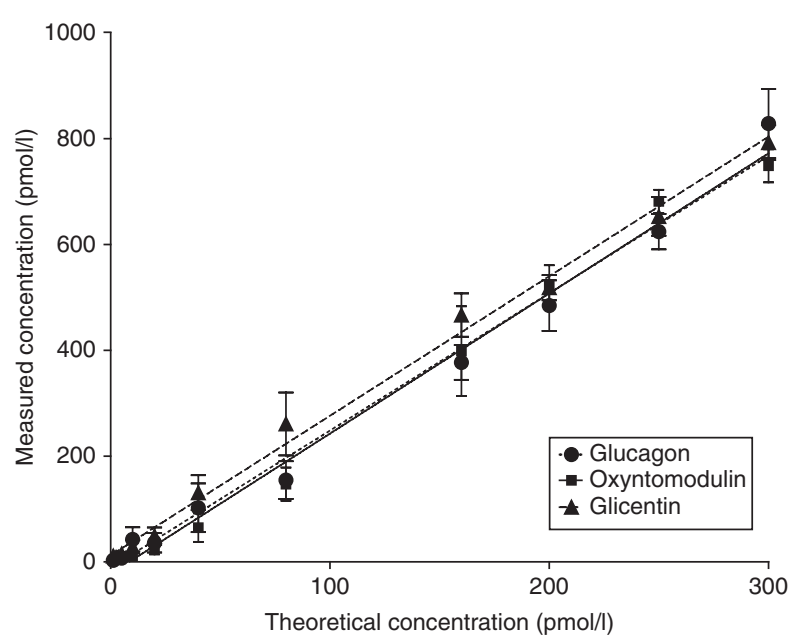

Figure 2

Results obtained in the assay with the Phoenix glucagon ELISA kit used for spiked buffer with glucagon 1-29, oxyntomodulin and glicentin. glucagon 1-29 - RIA: 95\% and QAAA: 92\%; oxyntomodulin - RIA: 67\% and QAAA: 74\%; and glicentin - RIA: 75\% and QAAA: 78\%.

\section{Specificity}

In assays carried out using the BlueGene and MyBioSource kits, there was no consistent recovery of any of the three peptides (including glucagon) in the spiked buffer, regardless of the concentration. Assays carried out using two USCN LIFE kits yielded zero results in the recovery experiments; therefore, we analysed their standards by RIA (4304), but found neither oxyntomodulin nor glucagon. The assay carried out using the Phoenix oxyntomodulin kit did not exhibit consistent recoveries for any of the peptides, including oxyntomodulin. The assay carried out using the Phoenix glucagon kit exhibited a linear and equal recovery (in buffer) of all the three peptides (Fig. 2), but, surprisingly, the measured recovery was consistently around 2.5-fold greater than the added amount of each peptide. These assays were not characterised further.

The assay carried out using the Millipore glucagon RIA kit exhibited a small cross-reactivity with oxyntomodulin (recovery $0.66 \%$ ) and glicentin (recovery $1.33 \%$ ) in the spiked buffer (Table 2). In the spiked plasma (Table 3), there was a similar small cross-reactivity with oxyntomodulin (recovery $1.66 \%$ ) and glicentin (recovery 1\%). The recovery of glucagon was relatively constant between kit batches in both buffer and plasma.

The assay carried out using the Bio-Rad Luminex kit exhibited some cross-reaction with oxyntomodulin (recovery 6.3\%) and glicentin (recovery 4\%) in the spiked plasma, although this was lower in the spiked buffer. It exhibited poor sensitivity (precluding measurement of the recovery of low concentrations), but detectable concentrations were variable and overestimated with a mean recovery of $282 \%$ in the spiked buffer. In the spiked plasma, the mean recovery of glucagon was $154 \%$.

The ALPCO assay kit is the only one on the market employing a standard microplate reader, whereas all other assays require special equipment. It exhibits an exaggerated recovery (215\%) in buffer. There was almost no crossreactivity with oxyntomodulin and glicentin. In plasma, the recovery of glucagon was, on average, $49 \%$.

\section{Precision and sensitivity}

Table 4 summarises the results of the precision analysis for the glucagon-specific assays. 
Table 2 Specificity and recovery of synthetic glucagon, oxyntomodulin and glicentin added to the assay buffer (spiked buffer) determined with assays carried out with commercially available kits.

\begin{tabular}{|c|c|c|c|c|c|c|c|}
\hline \multirow[b]{2}{*}{ Supplier } & \multirow[b]{2}{*}{ Peptide } & \multicolumn{3}{|c|}{$r^{2}$} & \multicolumn{3}{|c|}{ Recovery } \\
\hline & & Assay 1 & Assay 2 & Assay 3 & Assay 1 & Assay 2 & Assay 3 \\
\hline \multirow[t]{3}{*}{ Bio-Rad Luminex } & Glucagon & 0.87 & 0.94 & 0.94 & $276 \%$ & $174 \%$ & $396 \%$ \\
\hline & Oxyntomodulin & 0 & 0.24 & 0.00 & 0 & $1 \%$ & $0 \%$ \\
\hline & Glicentin & 0 & 0.14 & 0.00 & 0 & $0 \%$ & $0 \%$ \\
\hline \multirow[t]{3}{*}{ Millipore } & Glucagon & 0.99 & 0.99 & 0.99 & $58 \%$ & $41 \%$ & $40 \%$ \\
\hline & Oxyntomodulin & 0.69 & 0.56 & 0.50 & $1 \%$ & $1 \%$ & $0 \%$ \\
\hline & Glicentin & 0.84 & 0.87 & 0.81 & $1 \%$ & $2 \%$ & $1 \%$ \\
\hline \multirow[t]{3}{*}{ ALPCO } & Glucagon & $\begin{array}{l}0.99 \text { (24-h } \\
\text { incubation) }\end{array}$ & $\begin{array}{l}0.97(24-\mathrm{h} \\
\text { incubation) }\end{array}$ & $\begin{array}{l}0.99 \text { (48-h } \\
\text { incubation) }\end{array}$ & $\begin{array}{l}189 \% \text { ( } 24-h \\
\text { incubation) }\end{array}$ & $\begin{array}{l}229 \% \text { ( } 24-\mathrm{h} \\
\text { incubation) }\end{array}$ & $\begin{array}{l}228 \% \text { ( } 48-h \\
\text { incubation) }\end{array}$ \\
\hline & Oxyntomodulin & 0 & 0 & 0 & 0 & 0 & 0 \\
\hline & Glicentin & 0 & 0 & 0 & 0 & 0 & 0 \\
\hline \multirow[t]{3}{*}{ Phoenix } & Glucagon & 0.93 & 0.99 & 0.96 & $194 \%$ & $253 \%$ & $260 \%$ \\
\hline & Oxyntomodulin & 0.94 & 0.97 & 0.99 & $167 \%$ & $283 \%$ & $245 \%$ \\
\hline & Glicentin & 0.97 & 0.99 & 0.99 & $347 \%$ & $275 \%$ & $253 \%$ \\
\hline
\end{tabular}

The table indicates that widely different results are obtained for the (identical) baseline samples (i.e. before the addition of synthetic glucagon) in the three assays and for the three plasma pools. As has been mentioned, assays carried out using the Millipore and ALPCO kits were tested three times (with 5- to 6-month intervals) with three different batches and three different technicians/ researchers. The assay carried out using the Bio-Rad kit was tested only twice. The three sets of precision studies were comparable. In general, the coefficients of variation (CV) were large and recoveries of the added glucagon were non-linear and variable. For instance, the assay carried out using the Millipore kit nominally recognised the addition of $1 \mathrm{pmol} / 1$ glucagon, but could not distinguish between 10 and $20 \mathrm{pmol} / \mathrm{l}$ and measured the difference between 20 and $40 \mathrm{pmol} / \mathrm{l}$ as $3 \mathrm{pmol} / \mathrm{l}$ in the first set of experiments; as 0 in the second set; and as $7 \mathrm{pmol} / \mathrm{l}$ in the third set. Using this method for the evaluation of precision and sensitivity, all assays were found to perform poorly.

\section{Human samples}

Figure 3 shows the performance of assays carried out using three different commercial kits and the in-house RIA 4305 applied to identical samples drawn under hypoglycaemic and hyperglycaemic conditions. During hyperglycaemic conditions, the assay carried out using the Bio-Rad kit was not sensitive enough to detect any glucagon; however, during hypoglycaemic conditions, glucagon concentrations increased after $40 \mathrm{~min}$. The remaining assays exhibited the expected suppression during hyperglycaemic conditions and increases during hypoglycaemic conditions and in general the changes were parallel. Thus, it was mainly the basal concentrations that differentiated the assays. This is quantitatively illustrated by the results of correlation analyses in Table 5, where values obtained with the in-house assay generally correlated well with those obtained in the assay using the Millipore kit $(r=0.99-1.0)$, whereas the other assays typically yielded lower values.

Table 3 Specificity and recovery of synthetic glucagon, oxyntomodulin and glicentin added to human plasma (spiked plasma) determined with assays carried out with commercially available kits.

\begin{tabular}{|c|c|c|c|c|c|c|c|}
\hline \multirow[b]{2}{*}{ Supplier } & \multirow[b]{2}{*}{ Peptide } & \multicolumn{3}{|c|}{$r^{2}$} & \multicolumn{3}{|c|}{ Recovery } \\
\hline & & Assay 1 & Assay 2 & Assay 3 & Assay 1 & Assay 2 & Assay 3 \\
\hline \multirow[t]{3}{*}{ Bio-Rad Luminex } & Glucagon & 0.99 & 0.99 & 0.99 & $118 \%$ & $101 \%$ & $244 \%$ \\
\hline & Oxyntomodulin & 0.29 & 0.37 & 0.43 & $3 \%$ & $2 \%$ & $14 \%$ \\
\hline & Glicentin & 0.02 & 0.25 & 0.10 & $0 \%$ & $6 \%$ & $6 \%$ \\
\hline \multirow[t]{3}{*}{ Millipore } & Glucagon & 0.99 & 0.99 & 0.59 & $46 \%$ & $49 \%$ & $59 \%$ \\
\hline & Oxyntomodulin & 0.51 & 0.50 & 0.30 & $2 \%$ & $2 \%$ & $1 \%$ \\
\hline & Glicentin & 0.01 & 0.42 & 0.57 & $0 \%$ & $1 \%$ & $2 \%$ \\
\hline \multirow[t]{3}{*}{ ALPCO } & Glucagon & 0.85 & 0.99 & 0.97 & $80 \%$ & $42 \%$ & $24 \%$ \\
\hline & Oxyntomodulin & 0 & 0 & 0.17 & 0 & 0 & 0 \\
\hline & Glicentin & 0 & 0 & 0.38 & 0 & 0 & 0 \\
\hline
\end{tabular}


Table 4 Precision for glucagon assays. Each result represents mean \pm s.D. of 7-10 replicated determinations of glucagon concentrations in a pool $(n=5)$ of human plasma samples without and with the addition of known amounts of synthetic glucagon. For the Millipore and ALPCO kits, the analysis was repeated twice after 6 and 3 months using a new plasma pool, different assay batches and researchers (two lower panels). Average CV for standard curves: Millipore: 4-8\%; ALPCO: 2-8\%; and Bio-Rad: 10\%.

\begin{tabular}{|c|c|c|c|c|c|c|c|}
\hline & \multicolumn{7}{|c|}{ Added amount of glucagon (mean \pm s.D. in pmol/l) } \\
\hline & $0 \mathrm{pmol} / \mathrm{l}$ & $1 \mathrm{pmol} / \mathrm{l}$ & $2 \mathrm{pmol} / \mathrm{l}$ & $5 \mathrm{pmol} / \mathrm{l}$ & $10 \mathrm{pmol} / \mathrm{l}$ & $20 \mathrm{pmol} / \mathrm{l}$ & $40 \mathrm{pmol} / \mathrm{l}$ \\
\hline \multicolumn{8}{|l|}{ Company - run 1} \\
\hline Millipore RIA & $27 \pm 6$ & $28 \pm 9$ & $29 \pm 5$ & $28 \pm 6$ & $31 \pm 6$ & $32 \pm 8$ & $35 \pm 6$ \\
\hline ALPCO ELISA & $59 \pm 3$ & $63 \pm 3$ & $62 \pm 3$ & $63 \pm 2$ & $64 \pm 4$ & $65 \pm 2$ & $68 \pm 4$ \\
\hline Luminex Bio-Rad & $25 \pm 4$ & $34 \pm 7$ & $27 \pm 8$ & $35 \pm 15$ & $27 \pm 18$ & $19 \pm 27$ & $81 \pm 41$ \\
\hline \multicolumn{8}{|l|}{ Company - run 2} \\
\hline Millipore RIA & $7 \pm 3$ & $8 \pm 3$ & $8 \pm 3$ & $11 \pm 7$ & $13 \pm 5$ & $27 \pm 10$ & $27 \pm 13$ \\
\hline ALPCO ELISA & $147 \pm 37$ & $215 \pm 38$ & $215 \pm 48$ & $209 \pm 23$ & $212 \pm 19$ & $220 \pm 38$ & $238 \pm 22$ \\
\hline \multicolumn{8}{|l|}{ Company - run 3} \\
\hline Millipore RIA & $26 \pm 1$ & $26 \pm 1$ & $26 \pm 1$ & $28 \pm 1$ & $30 \pm 1$ & $35 \pm 3$ & $41 \pm 2$ \\
\hline ALPCO ELISA & $65 \pm 3$ & $64 \pm 2$ & $64 \pm 1$ & $64 \pm 3$ & $66 \pm 3$ & $68 \pm 1$ & $70 \pm 1$ \\
\hline
\end{tabular}

\section{Discussion and conclusion}

Assays for the pancreatic hormone glucagon have typically been carried out using RIAs, but specificity has always been a problem, as the same amino acid sequence is present in other endogenous peptides in addition to glucagon, as discussed in the Introduction. Sensitivity (i.e. the smallest concentration of a substance that can be reliably measured) is also a prominent issue, as circulating concentrations are likely to be low, around $10 \mathrm{pmol} / \mathrm{l}$ or less (22). The relevant changes in glucagon secretion, resulting from changes in plasma glucose concentrations, are also modest with increases in response to hypoglycaemia ranging from 20 to $30 \mathrm{pmol} / \mathrm{l}$, but even more challenging are decreases in response to hyperglycaemia,
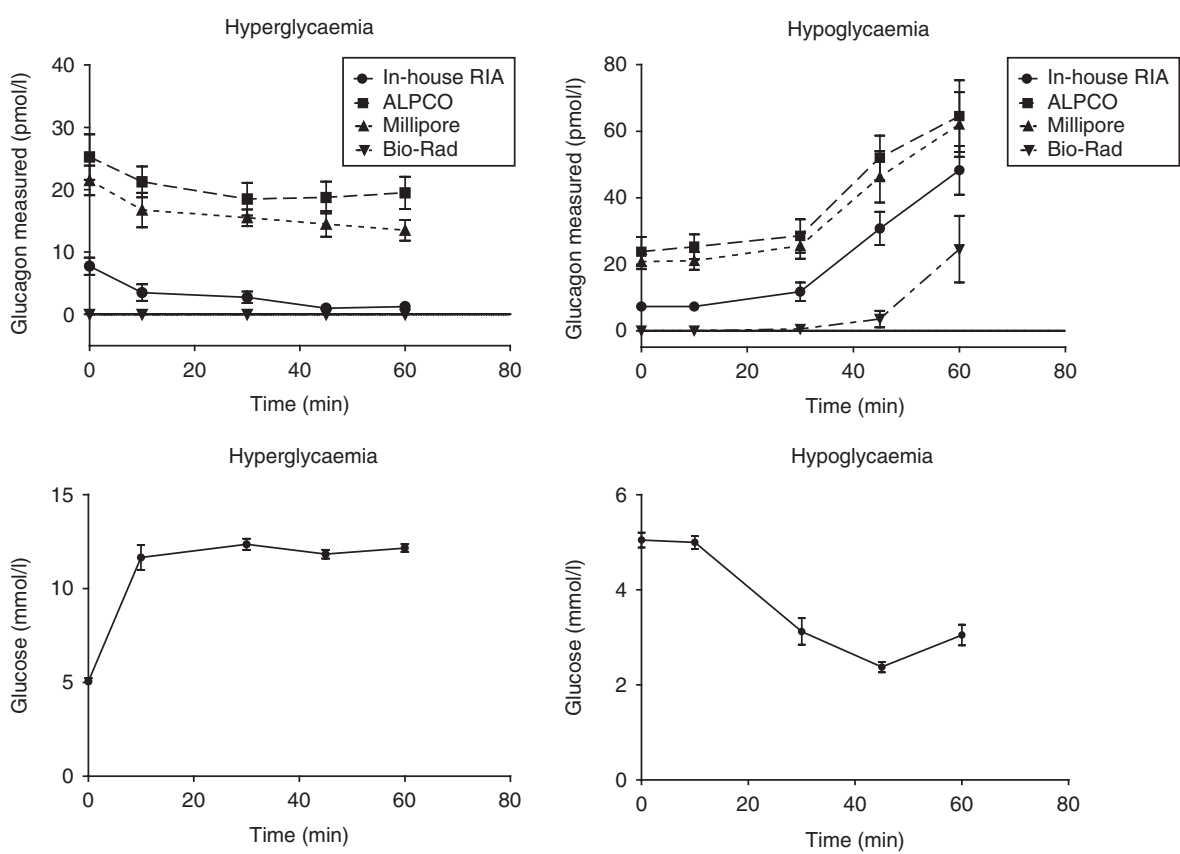

Figure 3

Glucagon concentrations in human plasma samples obtained under hypoglycaemic and hyperglycaemic conditions, measured with assays carried out using three commercially available glucagon kits and a validated in-house RIA. 
Table 5 Correlation coefficient $R^{2}$ between the different assays, derived from data presented in Fig. 3. Correlation was calculated (Pearson's distribution) with GraphPad Prism 5.

\begin{tabular}{|c|c|c|c|c|}
\hline & In-house RIA & ALPCO & Millipore & Bio-Rad \\
\hline \multicolumn{5}{|l|}{ Hyperglycaemia } \\
\hline In-house RIA & - & 0.94 & 0.99 & \\
\hline ALPCO & 0.94 & - & 0.94 & \\
\hline Millipore & 0.99 & 0.94 & - & \\
\hline \multicolumn{5}{|l|}{ Hypoglycaemia } \\
\hline In-house RIA & - & 0.99 & 1.00 & 0.91 \\
\hline ALPCO & 0.99 & - & 1.00 & 0.86 \\
\hline Millipore & 1.00 & 1.00 & - & 0.89 \\
\hline Bio-Rad & 0.91 & 0.86 & 0.89 & - \\
\hline
\end{tabular}

which may lower the concentrations to $1-2 \mathrm{pmol} / \mathrm{l}$ (24). Clearly, assays with sensitivities $>5 \mathrm{pmol} / \mathrm{l}$ are, therefore, unsuitable for the complete characterisation of glucagon secretion. The present study demonstrates that it is important to test a commercial assay carefully before being applied to precious and unique samples. This is not easy as the kit price is high, and often knowledge and training with respect to assay technology, peptide handling and instruments are required to obtain reliable and reproducible results. Moreover, the manufacturers do not always supply important and sufficiently detailed assay information. For instance, the Bio-Rad Luminex glucagon assay kit contained no specificity information, but, upon direct request, the manufacturer provided the information that there was no cross-reaction with GLP1 or glucose-dependent insulinotropic polypeptide, but gave no information about the more relevant peptides, oxyntomodulin and glicentin. In such cases, researchers are left to trust the commercial suppliers, but this is made more complicated by the fact that some companies provide related assay kits with different names, e.g. the Phoenix Ultra Sensitive Oxyntomodulin RIA Kit and Oxyntomodulin RIA Kit. It was impossible to retrieve any information about the difference between assays carried out using these two kits, and for the present study, we used the 'Ultra Sensitive' version. Moreover, the same assay kit seems to be sold under different names. For instance, the Cusabio Human Oxyntomodulin ELISA kit, Cat. no. CSB-E12948h appears to be identical to the MyBioSource assay kit. Similarly, the Yanaihara Institute, Inc., YK090 glucagon EIA kit appears to be identical to the ALPCO ELISA kit and performs similarly. Of further concern is the finding that some of the kits that we purchased appeared to be incapable of quantifying what they purported to. For instance, when measured with our in-house mid-region RIA, neither the glucagon nor the oxyntomodulin standards (only one oxyntomodulin kit was tested) provided with the USCN LIFE China kits for glucagon and oxyntomodulin contained measurable amounts of (correct) peptide. Given also that economical considerations may deter proper assay validation and influence the choice of assays, it must be suspected that many published results have been obtained with nonvalidated and/or inappropriate assays.

In the present study, we tested specificity by analysing the ability of assays to register relevant concentrations of glucagon, oxyntomodulin and glicentin in both buffer and plasma (the latter being clearly more demanding because of unspecific interference or other matrix effects). In addition, for the best of the assays, precision (i.e. the reproducibility of the result when the same sample is measured repeatedly, assessed using the $\mathrm{CV}$ ) was analysed formally by performing repeated measurements of samples spiked with small, increasing amounts of exogenous glucagon. Among the assays carried out using the ten assay kits examined in the present study, five performed so poorly in terms of sensitivity and precision that it was considered meaningless to characterise them further. Among the remaining assays, the assays carried out using the ALPCO and the Yanaihara Institute kits for glucagon appeared, as mentioned, to be identical and performed similarly; the assay carried out using the Phoenix glucagon kit cross-reacted equally with all the three peptides, which qualifies the assay for measuring 'total glucagon' but, of course, not for the measurements of glucagon in mixed samples. Thus, the assays carried out using the Millipore, the Bio-Plex and the ALPCO kits were the only ones with adequate specificity for glucagon measurement (although the assay carried out using the Bio-Plex kit did exhibit some cross-reaction with the gut peptides), and these were evaluated for precision and sensitivity. Their performance can also be evaluated from their ability to discriminate between low concentrations of glucagon in the specificity/recovery series. The assay carried out with the Millipore RIA kit had CV values around $7 \%$ for all the tested concentrations (1-40 pmol/l) and exhibited an intermediate linearity over the tested range; as a consequence, its sensitivity is probably not below $10 \mathrm{pmol} / \mathrm{l}$. The assay carried out with the ALPCO ELISA kit measured a very high concentration of glucagon in the plasma pool and had variable precision and a nonlinear recovery, with little difference between the results regardless of the added amount of glucagon (1-40 pmol/l). For these two kits (Millipore and ALPCO), similar results were obtained when the precision study was repeated by three different researchers or technicians, using a new 
plasma sample pooled during each study and new batches of assay reagents. The assay carried out with the Bio-Rad Luminex kit had a relatively high basal plasma value (27 pmol/l) and a very variable recovery with a very poor precision (CV ranging from 17 to $65 \%$ over the different concentrations tested).

During the completion of the study, we were informed by Millipore of a new glucagon assay kit, Cat. no. EZGLU-30K. It was too late to incorporate this in the full protocol, but we tested it with spiked buffer and plasma. The assay carried out using this kit is described as being a specific sandwich ELISA with a low cross-reactivity (3\%) with oxyntomodulin and glicentin. However, in our hands, it lacked sensitivity in the physiological range of glucagon concentrations (0-20 pmol/1). The regression coefficient $\left(r^{2}\right)$ dropped from 0.99 to 0.78 when using spiked plasma instead of spiked buffer, and it needs a high plasma volume of $150 \mu \mathrm{l}$ because of an extraction step. Plasma volume required for analysis has become an important issue, given the many studies currently carried out in rodents. For mouse studies, the volume available for assays cannot exceed 10-20 $\mu$ l plasma if the experiment involves just two blood samplings, because of the low blood volume of the animal. The volumes required for the three selected assays were $100 \mu$ l (Millipore), $50 \mu \mathrm{l}$ (ALPCO) and $15 \mu \mathrm{l}$ (Bio-Plex), rendering only the assay carried out using the Bio-Plex kit suitable for rodent studies.

When endogenous glucagon concentrations were measured in a series of biological samples to compare assays carried out using three commercial kits with our validated in-house RIA 4305, basal concentrations differed markedly, although the curves showed a similar pattern. Most probably, the differences in basal concentrations are due to different matrix effects and/or the presence of factors in the plasma that interfere in the assays in a nonspecific way. Our in-house RIA employed an ethanol extraction step to reduce this non-specific interference, without which basal levels would show a greater variation and be somewhat higher. None of the three selected assays requires an extraction step.

Based on the results of the present study, it can be concluded that none of assays carried out with the tested commercially available kits can measure human oxyntomodulin (or glicentin) concentrations with any reliability. The best-performing assay for glucagon is that carried out with the Millipore RIA kit, but its accuracy in the low concentration range does not appear to be adequate under conditions where, for instance, glucagon secretion is suppressed. In addition, the assay carried out with the
Millipore RIA kit requires a relatively large sample volume $(100 \mu \mathrm{l})$, which precludes its use in mouse experiments. Clearly, there is a need for improved glucagon assays.

Declaration of interest

The authors declare that there is no conflict of interest that could be perceived as prejudicing the impartiality of the research reported.

\section{Funding}

This study was funded by the NNF Center for Basic Metabolic Research, University of Copenhagen.

\section{Author contribution statement}

M J Bak, J J Holst, B Hartmann, N W Albrechtsen and J Pedersen planned and designed the study; $\mathrm{M} J$ Bak and N W Albrechtsen carried out the analyses; M J Bak, N W Albrechtsen and J J Holst wrote the manuscript; L O Dragsted, B Hartmann, C F Deacon, F K Knop and T Vilsbøll revised the manuscript; and M Christensen, F K Knop and T Vilsbøll provided physiological samples. All authors approved the final version of the manuscript.

\section{Acknowledgements}

The authors thank Thorkild Ploug and Bente Merete Stallknecht for the access and help with the Bio-Rad Luminex apparatus and technology. They also thank Sofie Pilgaard, who has been of outstanding high technical value for the study.

\section{References}

1 Bell GI, Santerre RF \& Mullenbach GT. Hamster preproglucagon contains the sequence of glucagon and two related peptides. Nature 1983302 716-718. (doi:10.1038/302716a0)

2 Holst JJ, Bersani M, Johnsen AH, Kofod H, Hartmann B \& Orskov C. Proglucagon processing in porcine and human pancreas. Journal of Biological Chemistry 1994269 18827-18833.

3 Rouille Y, Westermark G, Martin SK \& Steiner DF. Proglucagon is processed to glucagon by prohormone convertase PC2 in $\alpha$ TC1- 6 cells PNAS 199491 3242-3246. (doi:10.1073/pnas.91.8.3242)

4 Holst JJ. Gut glucagon, enteroglucagon, gut glucagon-like immunoreactivity, glicentin-current status. Gastroenterology 198384 1602-1613.

5 Ugleholdt R, Zhu X, Deacon CF, Orskov C, Steiner DF \& Holst JJ. Impaired intestinal proglucagon processing in mice lacking prohormone convertase 1. Endocrinology 2004145 1349-1355. (doi:10.1210/en.2003-0801)

6 Baldissera FG \& Holst JJ. Glucagon-related peptides in the human gastrointestinal mucosa. Diabetologia 198426 223-228. (doi:10.1007/ BF00252412)

7 Holst JJ. Evidence that enteroglucagon (II) is identical with the C-terminal sequence (residues 33-69) of glicentin. Biochemical Journal 1982207 381-388.

8 Brand CL, Jorgensen PN, Svendsen I \& Holst JJ. Evidence for a major role for glucagon in regulation of plasma glucose in conscious, nondiabetic, and alloxan-induced diabetic rabbits. Diabetes 199645 1076-1083. (doi:10.2337/diab.45.8.1076)

9 Holst JJ. The physiology of glucagon-like peptide 1. Physiological Reviews 200787 1409-1439. (doi:10.1152/physrev.00034.2006) 
10 Orskov C, Holst J, Knuthsen S, Baldiserra F, Poulsen S \& Nielsen OV. Glucagon-like peptides GLP-1 and GLP-2, predicted products of the glucagon gene, are secreted separately from pig small intestine but not pancreas. Endocrinology 1986119 1467-1475. (doi:10.1210/endo-1194-1467)

11 Mojsov S, Heinrich G, Wilson IB, Ravazzola M, Orci L \& Habener JF. Preproglucagon gene expression in pancreas and intestine diversifies at the level of post-translational processing. Journal of Biological Chemistry 1986261 11880-11889.

12 Muller WA, Faloona GR, Aguilar-Parada E \& Unger RH. Abnormal $\alpha$-cell function in diabetes. Response to carbohydrate and protein ingestion. New England Journal of Medicine 1970283 109-115. (doi:10.1056/ NEJM197007162830301)

13 Friis-Hansen L, Lacourse KA, Samuelson LC \& Holst JJ. Attenuated processing of proglucagon and glucagon-like peptide-1 in carboxypeptidase E-deficient mice. Journal of Endocrinology 2001169 595-602. (doi:10.1677/joe.0.1690595)

14 Unger RH, Aguilar-Parada E, Muller WA \& Eisentraut AM. Studies of pancreatic $\alpha$ cell function in normal and diabetic subjects. Journal of Clinical Investigation 197049 837-848. (doi:10.1172/JCI106297)

15 Toft-Nielsen MB, Madsbad S \& Holst JJ. Determinants of the effectiveness of glucagon-like peptide-1 in type 2 diabetes. Journal of Clinical Endocrinology and Metabolism 200186 3853-3860.

16 Ohneda A \& Ohneda M. Effect of glicentin-related peptides upon the secretion of insulin and glucagon in the canine pancreas. Tohoku Journal of Experimental Medicine 1988155 197-204. (doi:10.1620/tjem. 155.197)
17 Kirkegaard P, Moody AJ, Holst JJ, Loud FB, Olsen PS \& Christiansen J. Glicentin inhibits gastric acid secretion in the rat. Nature 1982297 156-157. (doi:10.1038/297156a0)

18 Cohen MA, Ellis SM, Le Roux CW, Batterham RL, Park A, Patterson M, Frost GS, Ghatei MA \& Bloom SR. Oxyntomodulin suppresses appetite and reduces food intake in humans. Journal of Clinical Endocrinology and Metabolism 200388 4696-4701. (doi:10.1210/jc.2003-030421)

19 Baldissera FG, Holst JJ, Knuhtsen S, Hilsted L \& Nielsen OV. Oxyntomodulin (glicentin-(33-69)): pharmacokinetics, binding to liver cell membranes, effects on isolated perfused pig pancreas, and secretion from isolated perfused lower small intestine of pigs. Regulatory Peptides 198821 151-166. (doi:10.1016/0167-0115(88)90099-7)

20 Vrang N \& Larsen PJ. Preproglucagon derived peptides GLP-1, GLP-2 and oxyntomodulin in the CNS: role of peripherally secreted and centrally produced peptides. Progress in Neurobiology 201092 442-462. (doi:10.1016/j.pneurobio.2010.07.003)

21 Baldissera FG \& Holst JJ. Glicentin 1-61 probably represents a major fraction of glucagon-related peptides in plasma of anaesthetized uraemic pigs. Diabetologia 198629 462-467. (doi:10.1007/BF00506540)

22 Holst JJ. Molecular heterogeneity of glucagon in normal subjects and in patients with glucagon-producing tumours. Diabetologia 198324 359-365.

23 Holst JJ. Evidence that glicentin contains the entire sequence of glucagon. Biochemical Journal 1980187 337-343.

24 Christensen M, Vedtofte L, Holst JJ, Vilsboll T \& Knop FK. Glucosedependent insulinotropic polypeptide: a bifunctional glucose-dependent regulator of glucagon and insulin secretion in humans. Diabetes 201160 3103-3109. (doi:10.2337/db11-0979)

Received 19 October 2013

Accepted 9 January 2014 